\title{
REDES SOCIALES, UN ARMA EMPLEADA A LA DELINCUENCIA
}

\author{
AUTORES: Rebeca Susana Andrade Baque ${ }^{1}$ \\ Kirenia Maldonado Zuñiga ${ }^{2}$ \\ Xiomara Lisbeth Anzules Ávila ${ }^{3}$ \\ Wilter Leonel Solorzano Alava ${ }^{4}$
}

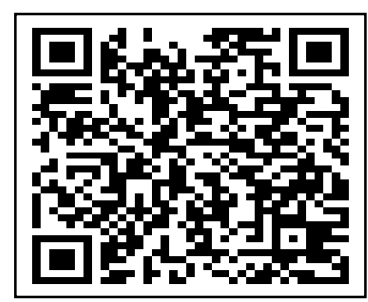

\section{DIRECCIÓN PARA CORRESPONDENCIA: (andrade-rebeca5470@unesum.edu.ec)}

Fecha de recepción: 10/02/2021

Fecha de aceptación: 24/09/2021

\section{RESUMEN}

En la presente investigación se analizó la poca importancia que le dan a las redes sociales en general, puesto a que es una manera de incidir a malas acciones de carácter delictivo a través de los medios tecnológicos, que son usados con dos fines, para el bien o para el mal, como pueden ser las amenazas, usurpación de identidad, creación de perfiles que no le corresponde, entre otras, el principal objetivo fue dar a conocer los riesgos y términos correspondientes, por lo cual es necesario sea aclarado de forma concisa y precisa, que es, como se da y que penalización van relacionada a cada uno de los delitos informático que el individuo puede causar, los ataques o ciberdelitos donde cuentan con infracciones usualmente se encaminan por efectuarse por medio de anonimatos para ejecutar el cometido, su metodología aplicada es la investigación, pues a través de esta se obtuvo información recopilada de varias fuentes, sus resultados según investigaciones e informes de la Policía, las bandas que toman esta iniciativa de tomar los datos personales de sus víctimas, lo hacen con el fin de aplicar la extorsión, el secuestro y los delitos más reportados son la trata de persona, la pornografía sexual y el acoso sexual, se concluyó que la principal vulnerabilidad de los delitos mediante las redes sociales son los usuarios que desconocen los procedimientos legales existentes, y que hasta ahora la mejor manera de evitar cualquier tipo de delitos que fueron mencionados es la prevención.

\footnotetext{
${ }^{1}$ Rebeca Susana Andrade Baque,estudiante de la carrera Tecnologías de la Información en la Universidad Estatal del Sur de Manabí, Jipijapa - Manabí - Ecuador. Bachiller en Químico Biólogo en la Unidad Educativa “COLPA”, Paján - Manabí - Ecuador. andrade-rebeca5470@unesum.edu.ecORCID:https://orcid.org/0000-0003-0772-9809

${ }^{2}$ Kirenia Maldonado Zuñiga,Máster en Ciencias de la Educación, Licenciada en Educación Informática. Docente de la carrera en Ingeniería en Tecnologías de la Información. Universidad Estatal del Sur de Manabí. Jipijapa, Manabí, Ecuador. kirenia.maldonado@unesum.edu.ec.

${ }^{3}$ Xiomara Lisbeth Anzules Ávila, estudiante de la carrera Tecnologías de la Información en la Universidad Estatal del Sur de Manabí, Jipijapa - Manabí - Ecuador.Bachiller en Administración de Sistemas en el Colegio Fiscal Técnico”Dr. Isidro Ayora Cueva” Isidro Ayora-Guayas-Ecuador.anzules-xiomara8108@unesum.edu.ec.

${ }^{4}$ Wilter Leonel Solorzano Alava,estudiante de la carrera Tecnologías de la Información en la Universidad Estatal del Sur de Manabí, Jipijapa - Manabí - Ecuador. Bachiller en Ciencias en la Unidad Educativa “Fanny de Baird”, Bahía de Caráquez - Manabí - Ecuador. solorzano-wilter7647@unesum.edu.ec.
} 
Rebeca S. Andrade Baque, Kirenia Maldonado Zuñiga, Xiomara L. Anzules Ávila, Wilter L. Solorzano Alava

PALABRAS CLAVE: delitos; información; riesgos; tecnológicos; vulnerabilidad.

\title{
SOCIAL NETWORKS, A WEAPON USED FOR CRIME
}

\begin{abstract}
In this research, the little importance they give to social networks in general will be analyzed, since it is a way of influencing bad actions of a criminal nature through technological means, which are used for two purposes, to good or bad, such as threats, identity theft, creation of profiles that do not correspond, among others, them a in objective is to public zitherists and corresp on ding terms, for which it is necessary to clarify in a way concise and precise, what itis, how it is given and what penalty is related to each of the computer crimes that the individual can cause, attacks or cybercrimes that have infractions are usually directed to be carried out by means of anonymity to execute the task, Its applied methodology is investigation, because through this information collected from various sources was obtained, its results according to investigations and reports of the Police, the bands as that take this initiative to take the personal data of their victims, they do it in order to apply extortion, kidnapping and the most reported crimes are human trafficking, sexual pornography and sexual harassment, it is concluded that them a invulnerability of crimes through social networks are users who are unaware of the existing legal procedures, and that until now the best way to avoid any type of crime that will be mentioned in the prevention.
\end{abstract}

KEYWORDS: crimes; information; risks; technological; vulnerability.

\section{INTRODUCCIÓN}

En la actualidad las redes sociales son catalogadas como un tema mundial, tanto en niños, jóvenes y adultos que usan este medio de varias formas, que muchas veces pueden ser representadas como un peligro debido a su mal uso, en ocasiones no se percatan en poder leer detenidamente los términos y condiciones al momento de empezar a utilizar una red social o al crearla. Los padres permiten entrar a sus hijos a sitios no permitidos, en los que pueden dar información y esta puede ser usada de manera indebida. (Rd Station, 2017)

Las redes sociales no son representadas como un peligro para la sociedad, pues estas cuentan con herramientas y funciones que puedan llegar a ser seguras, notamos la diferencia en cuanto las personas en la calle nos aferramos a no dar información de nuestros datos personales, pero al crear perfiles en internet, fácilmente estamos accediendo a entregarle una mina de datos a los delincuentes (Mar et al., 2020), (Fonseca et al., 2020), (Mar et al., 2021).

En el presente artículo se analizará cual es la incidencia y peligro que pueden llegar a tener las redes sociales tanto en niños, jóvenes y adultos, que son víctimas de delincuencia. El problema radica en que dichas redes son aprovechadas para cometer actos ilícitos, es por aquello que a través de este estudio no solo serán mencionados algunos medios de prevención, sino también se emplearan puntos importantes que los delincuentes informáticos usan para lograr su objetivo y obtener sus beneficios.

64 UNESUM-Ciencias. Publicación cuatrimestral. Vol. 5, Año 2021, No. 6 (Especial Ingenierías) 


\section{DESARROLLO}

\section{¿QUÉ SON LAS REDES SOCIALES?}

Las redes sociales, en el mundo virtual, son sitios y aplicaciones que operan en niveles diversos como el profesional, de relación, entre otros - pero siempre permitiendo el intercambio de información entre personas y/o empresas.

Cuando se habla de red social, lo que viene a la mente en primer lugar son sitios como Facebook, Twitter y LinkedIn o aplicaciones como Snapchat e Instagram, típicos de la actualidad, pero la idea, sin embargo, es mucho más antigua: en la sociología, por ejemplo, el concepto de red social se utiliza para analizar interacciones entre individuos, grupos, organizaciones o hasta sociedades enteras desde el final del siglo XIX.

En Internet, las redes sociales han suscitado discusiones como la de falta de privacidad, pero también han servido como medio de convocatoria para manifestaciones públicas en protestas, estas plataformas crearon, también, una nueva forma de relación entre empresas y clientes, abriendo caminos tanto para la interacción, como para el anuncio de productos o servicios. (Marketing de Contenido de RD Station, 2017), (Mar et al., 2015), (Cornelio \& Gulín, 2018).

\section{RIESGOS AL DAR INFORMACIÓN EN LAS REDES SOCIALES}

De acuerdo con estas investigaciones, este tipo de hábitos se dan más entre los jóvenes, quienes ponen una gran cantidad de información personal que queda vulnerable.

\section{Pérdida de datos}

Los usuarios de las redes sociales que comparten más información son más propensos a sufrir la pérdida de datos en comparación con aquellas que no lo hacen.

De los que comparten datos, cerca del $50 \%$ ha sufrido la pérdida de datos en sus teléfonos inteligentes, $52 \%$ desde su computadora y $20 \%$ desde su tableta.

\section{Información que llega a desconocidos}

Cuando pierdes tu dispositivo, también, pierdes valiosos datos con ellos, como las contraseñas almacenadas, lo que permite a otros tener acceso a tu vida digital.

Por ello, es recomendable que cambies tus contraseñas periódicamente y tomes todas las precauciones para evitar extraviar tu celular. Así mismo, en caso sufras el robo de tu teléfono móvil o lo pierdas, debes dar cuenta de inmediato a tu operador de servicio para hacer el bloqueo de la línea y el aparato en sí. De esa forma, le darás menos chance a extraños de acceder a tu información personal.

\section{Estás más expuestos a los hackers}

Lo hackers están al acecho en la red, por ello, la sugerencia es que no compartas muchos datos personales ni financieros a través de las redes sociales, aquello se convertirá en víctima potencial de los hackers.

Es importante que recuerdes que toda información que compartas a través de las redes sociales es pública y, por lo tanto, cualquiera puede acceder a ella.

\section{Facilidad de rastreo}

Compartir fotos o videos de tus viajes o los lugares que más frecuentas en tu día a día permitirá a los delincuentes poder rastrearte con facilidad y convertirte en una de sus víctimas.

Toma en cuenta, además, que cada vez que compartes información sobre tus visitas a lugares, también, estás dando el dato de que no estás en casa, información que puede ser aprovechada por los amigos de lo ajeno. (ANÓNIMO, 2018). 


\section{DELINCUENCIA}

Es todo aquello relacionado con las acciones delictivas y con los individuos que las cometen, conocidos como delincuentes. La palabra, como tal, proviene del latín "delinquentia". Los delincuentes son personas que cometen delitos, es decir, que realizan acciones contrarias a lo que establece la ley y el derecho, y que por ellas son penados por el sistema de justicia de cada país, lo que implica el cumplimiento de castigos o sanciones dependiendo de la gravedad de la falta.

El Estado es el encargado de proteger a los ciudadanos contra la delincuencia, creando órganos de vigilancia y control social, como la policía, y aplicando la ley mediante el sistema de justicia, las penas aplicadas sobre los delincuentes contemplan, por lo general, la prisión, y persiguen como ideal la reinserción social de los individuos que han cometido actos delictivos, para que puedan volver a ser elementos productivos de esta. (ANÓNIMO, 2017).

\section{DELITOS PENALES}

Los principales delitos e ilícitos que se pueden llevar a cabo por medio de las redes sociales y que atentan, sobre todo, contra el derecho fundamental al honor, a la intimidad y a la propia imagen.

\section{- Sexting}

Uno de los delitos penales que puede configurarse por medio de las redes sociales es el sexting, que consiste en el envío de imágenes o mensajes de texto con contenido sexual a otras personas por medio de teléfonos móviles. Si bien en sí mismo este acto no es ilegal, cuando se trata de menores de edad o cuando el adulto no consiente esa actividad, constituye un ilícito penal (artículo 197 del Código Penal).

\section{- Hostigamiento o Stalking}

En segundo lugar, es necesario remitirse al hostigamiento o stalking como otro de los comportamientos que se puede presentar por el uso de las redes sociales. El hostigamiento como delito penal se introdujo en el artículo 172 numeral 1 de la Ley Orgánica 1/2015 de 30 de marzo, la cual tipificó un nuevo delito contra la libertad, que es el denominado delito de acoso, este delito se presenta cuando hay un acoso constante de una persona que vigila, persigue y se contacta con otra, a través de medios electrónicos, como puede ser mediante redes sociales. Se castiga el acoso hacia otra persona teniendo en cuenta que la conducta de stalking altera gravemente el desarrollo de la vida cotidiana del afectado, limitando su libertad al obrar, sin que el mero sentimiento de temor o molestia sea punible.

\section{- Injurias y Calumniar.}

Por un lado, la calumnia es la imputación de un delito hecha con conocimiento de su falsedad o temerario desprecio hacia la verdad (artículo 205 del Código Penal) y por el otro, la injuria es definida como la acción o expresión que lesionan la dignidad de otra persona, menoscabando su fama o atentando contra su propia estimación (artículo 208 del Código Penal).Para el caso de estos delitos habrá que determinar si la persona que está haciendo las acusaciones y manifestaciones lo hace dentro del ejercicio de la libre expresión o se está extralimitando y por tanto, violando el derecho al honor, a la intimidad y propia imagen del afectado.

\section{- Ilícitosciviles}

La Ley Orgánica 1/1982, de 5 de mayo, de protección civil del derecho al honor, a la intimidad personal y la propia imagen, otorga una protección vía civil a estos derechos frente a las

66 UNESUM-Ciencias. Publicación cuatrimestral. Vol. 5, Año 2021, No. 6 (Especial Ingenierías) 
injerencias o intromisiones que resultan de una extralimitación al derecho a la libre expresión. El artículo 7 de esta Ley, establece los siguientes ilícitos civiles que puede cometerse por medio de las redes sociales:

La divulgación de hechos relativos a la vida privada de una persona o familia que afecten a su reputación y buen nombre, así como la revelación o publicación del contenido de cartas, memorias u otros escritos personales de carácter íntimo.

\section{- Área Digital Abogados}

Área Digital Abogados cuenta con un equipo de abogados especialistas en derecho de las nuevas tecnologías y protección de datos con sede en Barcelona, que ofrece sus servicios profesionales para sus clientes españoles y extranjeros que operen en territorio nacional. (Área Digital Abogados, 2018).

\section{MATERIALES Y MÉTODOS}

Se manejó los métodos de investigación científica, influyendo el método de inducción y análisis - síntesis, estos métodos son con la finalidad de examinar cada uno de la información recopilada para de esta forma poder obtener un resultado favorable mediante la búsqueda, y a su vez favorecer el conocimiento y disminuir los errores que se pueden llegar a cometer al trazar la línea de soltar información en la que se pueda ver en peligro, y así mismo los métodos bibliográficos, al conocer cada antecedente que brindo el trabajo de investigación.

\section{RESULTADOS Y DISCUSIÓN}

Como resultado obtenido al tema requerido ayudo a enriquecer el escaso conocimiento de los jóvenes y niños que desconocían los peligros que puede abordar el mundo de la red social, a pesar que las redes no representan ni un riesgo siempre y cuando esta sea usada de una manera responsable y bajo supervisión, es necesario leer detenidamente cada termino o condición que generan los sitios al pedir datos personales, cabe recalcar que los dispositivos móviles facilitan el acceso rápido a las redes sociales, haciendo de este un medio de comunicación flexible para ser uso en cualquier momento y lugar, pero así mismo dedican mucho tiempo a estar conectado en las redes sociales olvidando sus obligaciones, y sus padres sin saber que hacen o con quien interactúan o entregan información valiosa, el objetivo principal es evitar que haya víctimas de los delitos anteriormente mencionados, pues mediante estudios se obtuvo que los delitos informáticos actualmente se los realiza por medio de la plataforma de Facebook a través de cuentas falsas, siendo esta como la más vulnerable a datos e información sumamente personal.

\section{CONCLUSIONES}

Las redes sociales a pesar que es una forma de interactuar, también pueden crear conflictos, pues esta permite ciertas relaciones con terceras personas que no buscan un bien.

Es necesario realizar una lectura relevante al instalar una app, también al dar datos personales a un sitio web o al crear un perfil en cualquier plataforma.

El mantener los datos personales seguros, nos beneficia en todos los aspectos y nos evita de los posibles ataques. 


\section{REFERENCIAS BIBLIOGRÁFICAS}

Anonimo. (04 de ABRIL de 2017). Obtenido de Significados.com: https://www.significados.com/delincuencia/\#: :text=Qu\%C3\%A9\%20es\%20Delincuencia\%3A,tal\%2C\%20p roviene\%20del\%20lat\%C3\%ADn\%20delinquentia.

Anonimo. (19 de Noviembre de 2018). Riesgos de publicar demasiados datos en redes sociales. Obtenido de Liderman.com.pe: https://www.liderman.com.pe/blog-riesgos-publicar-datos-redes-sociales/

Área Digital Abogados. (2018). Delitos en Redes Sociales: Sexting, Stalking e Injurias. Obtenido de

Adabogados.net: https://adabogados.net/delitos-en-redes-sociales-sexting-stalking-e-injurias/

Marketing de Contenido de RD Station. (12 de Marzo de 2017). Redes Sociales. Obtenido de Rdstation.com: https://www.rdstation.com/es/redes-sociales/

Rd Station. (12 de Marzo de 2017). Rd Station. Obtenido de rdstation.com: https://www.rdstation.com/co/redessociales/

Cornelio, O. M., \& Gulín, J. G. (2018). Modelo para la evaluación de habilidades profesionales en un Sistema de Laboratorios a Distancia. Revista Científica, 3(33), 1.

Fonseca, B. B., Cornelio, O. M., \& Pupo, I. P. (2020). Linguistic summarization of data in decision-making on performance evaluation. 2020 XLVI Latin American Computing Conference (CLEI), 268-274. https://ieeexplore.ieee.org/abstract/document/9458370/

Mar, O., G, G., Ching, I., \& Bron , B. (2020). Remote Laboratory System for Automatic Engineering. International Journal of Wireless and Ad Hoc Communication, 1(2), 55-63. http://www.americaspg.com/articleinfo/2/show/806

Mar , O., Gulín , J., Bron , B., \& Garcés , V. (2021). Sistema de apoyo al diagnóstico médico de COVID-19 mediante mapa cognitivo difuso. Revista Cubana de Salud Pública, 46, e2459. https://www.scielosp.org/article/rcsp/2020.v46n4/e2459/es/

Mar, O., Véliz, Y. Z., Felipe, M. d. R. C., \& Vázquez, M. L. (2015). Motor de inferencia decisional en sistema informático para la evaluación del desempeño. Revista Cubana de Ciencias Informáticas, 9(4), 16-29.

68 UNESUM-Ciencias. Publicación cuatrimestral. Vol. 5, Año 2021, No. 6 (Especial Ingenierías) 